\title{
WAREHOUSHING AND INVENTORY INFORMATION SYSTEM MODEL USING RADIO FREQUENCY IDENTIFICATION (RFID) IN EASTERN NAVAL WAREHOUSING
}

\author{
Indra Agustian ${ }^{1}$, Eka Muktiono² $^{2}$ Akhmat Nuryadin ${ }^{3}$, Bambang Suharjo $^{4}$ \\ 1,2,3,4 Indonesian Naval Technology College, \\ STTAL-Bumimoro-Morokrembangan, Surabaya 60187, Indonesia
}

\begin{abstract}
Eastern Naval Warehousing is the technical implementation elements in charge of receiving, storing, maintaining and distributing supplies to support existing user in the Navy in particular user located in the eastern region. To support the operational activities of the Navy, Eastern Naval Warehousing as service organizations should be supported with the provision of an information system capable of supporting the activities become more optimal provisioning. Speed and accuracy of support provision to user is an indication for the success of a service. Information technology nowadays has grown very rapidly to develop into the current warehousing system. RFID (Radio Frequency Identification) is the process of identifying an object automatically by Radio Frequency. There are two important components of an RFID system is the card (tag) and the reader. Application warehousing information system can be integrated with RFID technology, so that the system can run more optimal for warehousing system. This research aims to design warehousing information system based on RFID in Eastern Naval Warehousing used in processing existing warehousing system to gain optimal in provisioning operations running in Eastern Naval Warehousing to support provisioning activities to meet the requirement of existing user in Navy. Field studies conducted in Eastern Naval Warehousing, aimed to determine the current state of warehousing system that runs to identify existing problems. Furthermore, to process the data, created the design of an information system based on RFID warehousing in software system. This paper get to report out of the goods, report the amount of inventory in real time, the location of goods and EOQ value of goods to determine the optimal inventory level of each item.
\end{abstract}

Keywords: RFID, Warehousing and Inventory Information System, Eastern Naval Warehousing

\section{INTRODUCTION.}

one of Eastern Naval Warehousing's work is to receive, store, maintain and distribute inventory. Eastern Naval Warehousing's service as an organization that has a tendency to supply services both for incoming and outgoing supplies use a lot of data processing even though it has been computerized, in carrying out inventory in Eastern Naval Warehousing assisted by automated and computerized warehousing information systems, Eastern Naval Warehousing supply automation is carried out to support speed and accuracy of inventory support to users, existing information systems are not found in each Eastern Naval Warehousing warehouse, so there is often inaccurate data on existing items. The recording and checking of goods in the Eastern Naval Warehousing is done manually. The recording process is done by writing the specifications of the goods that enter and exit the warehouse at the memorandum of goods while checking the goods is done by looking at the physical goods and counting the number of items one by one every time there are items that will enter and exit the warehouse. This method of recording has many weaknesses. These weaknesses include frequent errors in writing 
(human error). With this kind of system, when there are large quantities of goods entering and leaving the warehouse, a long queue buildup will occur. The length of the process of recording and checking as well as handling nonconformities between the evidence of goods with existing goods will cause a long queue of goods because they must be examined and managed first. In addition, the storage process uses a stock card that is stored in a shelf or archive box so that the search process requires a long time so it is not efficient and also the location of the warehouse is far from administrative arrangements so that the supervision of the number of goods inventory is not optimal. And also the lack of inventory information needed by the user so that it must submit a procurement and even though the item can be requested at Eastern Naval Warehousing. Then in the supply using the manual method that is by conventional means, done by checking the stock of goods that have been used up.

There are several alternatives that can be chosen to replace the manual method, namely using magnetic cards, RFID electronic cards, smart cards, and barcodes. Of the several methods available, the use of RFID is very fast, concise and efficient in helping information systems in warehousing. RFID is part of the auto-identification technology which also includes barcodes. RFID consists of 2 parts, namely Transponder and Reader. The transponder attaches to the product and is then identified by the reader. Transponders can be Card, Tag, or Wristband. According to (Bill, 2008) RFID has advantages over barcodes including RFId technology does not require infrared light, hundreds of tags can be identified at one time, can read hundreds of tags per second, RFID tags can store more data and data on RFID can be adjusted according to needs.

For this reason, this paper makes a warehouse information system based on RFID, so that the application system can be used in each dopusbektim warehouse, even though the distance is far from the service office, but the authorized leader can use it as a media to more accurately monitor real time stock search for the location of goods faster and easier, inventory information needed by users is easier and can determine the optimum number of orders .So that the warehousing system runs more efficiently.

\section{MATERIAL/METHODOLOGY.}

\subsection{Basic System Concepts}

The system is a network of procedures that are interconnected, gathered together to carry out an activity or to complete a certain goal (Fitzgerald, 1981). then define the procedure as follows:

"A procedure is the exact sequence of the stages of instruction that explain (what) to do, (who) does it, (when) is done and (how) to do it".

System approach is a collection of elements - elements or components is a broader definition and more widely accepted. Because the system approach that emphasizes the component will be easier to learn and easier in designing a system and in fact a system can consist of several subsystems. Components - components or subsystems - subsystems in a system interact and interact to form a unit that cannot stand alone.

Learning a system will be more profound if you know in advance what a system is. To analyze and plan a system, analysts and system designers must first understand the components or elements or subsystems of the system. 
The system mechanism in general can be seen in Figure 2.1.

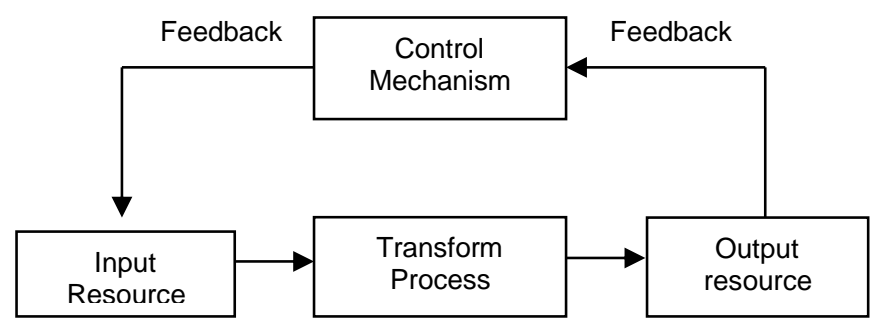

Figure 2.1 System Mechanism (McLeod, 2004)

From the picture it can be seen, that the system consists of the following elements:

a. Input resources, which can be in the form of raw materials, human energy or information. Input is input material which will later be converted through a process into an output.

b. Transformation process, which is a process to change or add value to an input into an output that has meaning and usefulness.

c. Output, is the result of input processing and can be input for other systems or the system itself as feedback. Can be in the form of services, materials, information and so on.

d. Feedback and control mechanisms, can be interpreted as observers of the transformation process to function according to purpose. The feedback loop here functions to connect resources with a controlling mechanism, which is sending information from the output to the control mechanism and sending a comparative signal to the input if the operating system needs to be changed (Hartono, 2005)

\subsection{Basic Concept of Information}

Information can be defined as the result of processing data in a form that is more useful and more meaningful to the recipient who describes a real event that is used for decision making. Information is data that has been processed into a form that is more useful and more meaningful for those who receive it,
The value of information in information is said to be valuable if the benefits are more effective than the cost of obtaining it and most of the information cannot be accurately estimated in terms of the value of money, but can be estimated the value of its effectiveness. Information is the result of processing data that has meaning, usually tells an unknown thing to the user (McLeod, 2004)

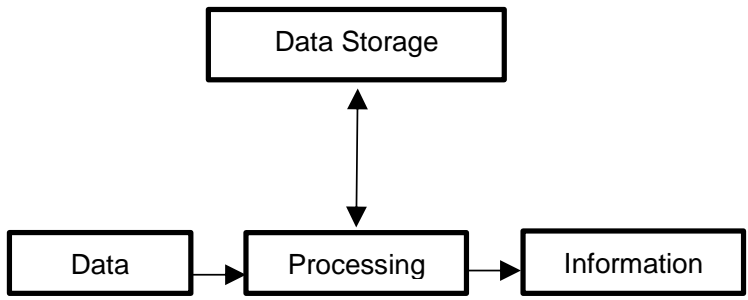

Figure 2.3 Transforming Data into Information (McLeod, 2004)

\subsection{Siklus Informasi.}

To obtain useful information for recipients, it is necessary to explain how the cycle that occurs or is needed in producing information. First of all the data is still raw and has not been able to give a lot of meaning to the user inserted into the model which generally has a certain process sequence and certain, after processing it will produce certain information that is easy to understand, understand and well received that is beneficial to the recipient (level management) as a basis for making a decision or taking action. From the decision or action will produce or obtain certain events that will be used again as data that will later be included in the model (process), and so on. Thus it will form an information cycle. This activity continues continuously so that it becomes an information cycle. The information cycle can be seen in Figure 2.4 below: 


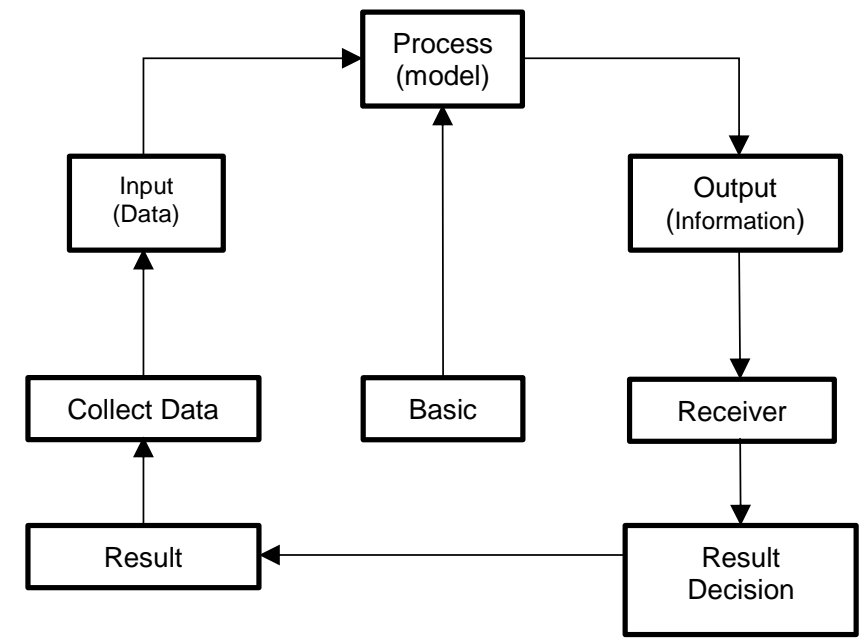

Figure 2.4 Information Cycle (McLeod, 2004)

\subsection{Basic Concepts of Information Systems}

(Burch \& Grudnitski, 1986) suggest that information systems consist of components which he calls the building blocks. The building block consists of:

a. Block Input (Input), the input represents the data entered into the information system. Input here includes methods and media to capture the data to be entered, which can be in the form of basic documents.

b. Block Model, this block consists of a combination of procedures, logic and mathematical models that will manipulate input data and data stored in the database in a certain way to produce the desired output.

c. Output Blocks, Products of information systems are outputs that are quality information and documentation that is useful for all levels of management and user systems.

d. Block technology, technology is divided into 3 main parts, namely technicians (humanware or braiware), software (software) and hardware (hardware). e. Database Blocks, Database (Database)

is a collection of data that are interconnected with one another, stored on a computer and used software to manipulate it.

f. Control Blocks, Some controls need to be designed and implemented to ensure that things that can damage the system can be prevented or if errors can be overcome immediately.

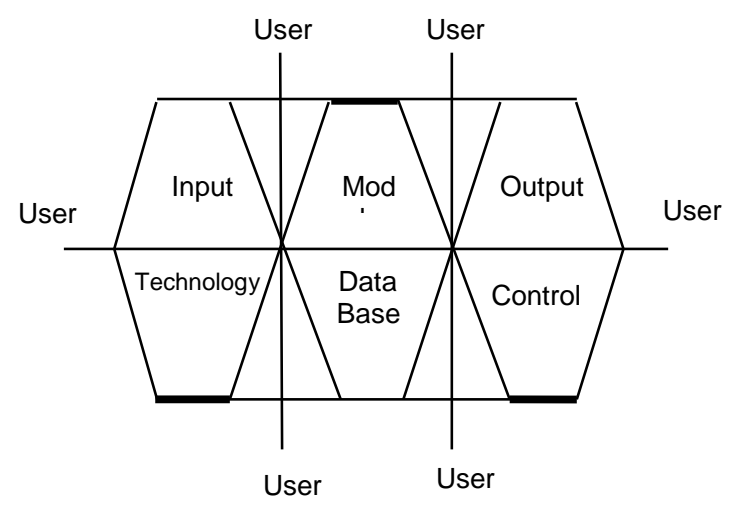

Figure 2.5 Block Information Systems (McLeod, 2004)

\subsection{Radio Frequency Identification (RFID).}

Radio Frequency Identification (RFID) is a wireless or wireless technology that is used to identify someone or an object by using radio transmission frequencies. RFID technology consists of two main components, namely RFID-reader and RFID-tag. In general, RFID-tags have a shape and size such as tags or ATM cards, this tag functions as a transponder which is a combination of functions from the transmitter and responder and inside it has special information in the form of a collection of unique characters from hexadecimal numbers. RFID-reader functions as a special information reader that is transmitted through a special frequency of an RFID-tag and this tool can only read special 
information from compatible RFID-tags. (Hamid, 2010).

The working mechanism that occurs in an RFID system is that a radio frequency reader scans the data stored in the tag, then sends that information to a database that stores the data contained in the tag. The RFID system is a type of automatic identification system that aims to allow data to be transmitted by portable devices called tags, which are read by an RFID reader and processed according to the needs of a particular application. Data transmitted by tags can provide identification or location information, or specific things about tagged products, such as price, color, date of purchase and others

RFID-based systems will require several components in the form of a device to function as an information system and identification of certain objects. Each procurement component is tailored to the needs of the application system to be made. The main components of RFID-based application systems are as follows:

a. RFID-reader, an RFID-tag reader that is active (has a power supply) and emits signals or radio frequency frequencies in certain frequencies to be read by compatible RFID-tags. In addition, the task of RFIDreader is to pass information from RFID-tags to a computer system or microcontroller that functions as a tool for data and information received so that it can be used according to system requirements.

b. RFID-tags, an RFID device that will be active when receiving a signal emission or compatible radio wave frequency from an RFID-reader. In RFID-tags there are unique data and information stored in memory, while the forming components consist of electronic circuits and antennas integrated in the RFID-tag series.

c. Computer / Microcontroller, used as a tool to create and store RFID-based applications. Of course this computer will receive data from an RFID-tag via an RFIDreader connected to it, after that the data is used or processed in accordance with the business application system created.

The level of accuracy of RFID can be defined as the success rate of RFID-tags to identify an RFID-tag that is in the field of the working system. The level of accuracy of the ability of the identification process is strongly influenced by several physical limitations as follows:

a. Position of RFID reader.

b. Characteristics and material of the RFID system work environment.

C. Power supply conditions and limits.

d. Frequency of RFID work

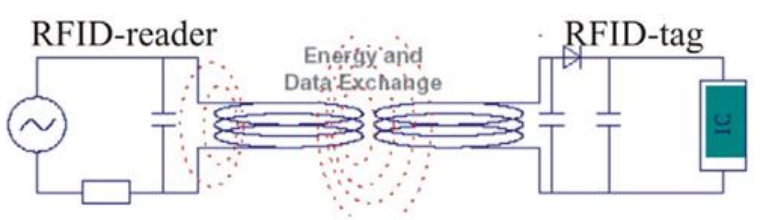

Figure 2.6 How the RFID system works (www.gao.gov)

In Figure 2.6 explains how an RFID-tag is read by an RFID-reader. For this reason RFID-tags and RFID-readers must have compatible or the same working frequency. In this final project, an RFID reader system with a working frequency of $125 \mathrm{KHz}$ is used for RFID-EM4001 format tags / the like. The more complete explanation of the workings of RFID system technology is as follows:

a. The RFID-reader will emit radio signals / waves in certain frequencies (according to compatible RFID devices) continuously and constantly. 
b. RFID-tags which have information in the form of a collection of several characters of hexadecimal numbers are brought close to the field of the radio wave frequency signal broadcast area of the RFID-reader.

c. RFID-tags that are in the field area of the radio wave frequency signal from the RFIDreader will be automatically active. If the conditions of the transmitted wave frequency are compatible then the RFID-tag will issue a signal or radio wave frequency to reply by sending unique information contained therein. d. After the above process is running then RFID-reader will process it by sending the unique information into a computer system or microcontroller to be processed into information in accordance with the design of the RFID-based application.

\subsection{Research Methodology}

The outline of all activities carried out during this research took place illustrated in the flow Chart as described in Figure 2.7.

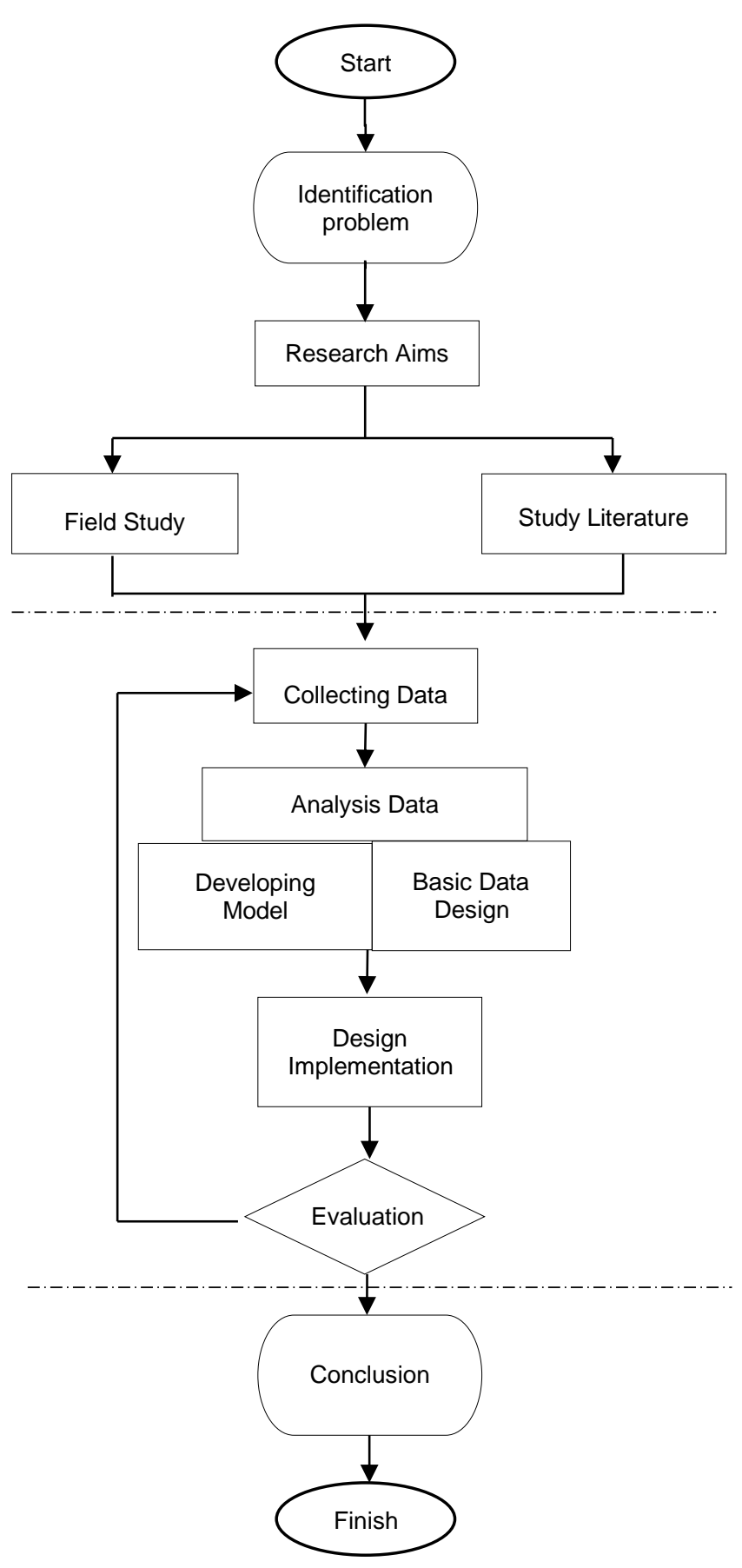

Figure 2.7 Flow Chart of Design Methodology

\subsection{Design and Implementation Phase}

This is an advanced stage carried out to analyze and develop data that has been collected at the preparation stage.

Activities carried out include:

a. System analysis. This activity is to find out the current system and procedure for 
warehousing in Dopusbektim, in addition to knowing the analysis of system requirements. When analyzing the system, there will be indirect weaknesses in the system. The aim is to identify any deficiencies contained in the current system, to then make corrective steps.

b. Model Development. Done to get a formulation from a real system in a certain form that is expected to help in solving problems. A model can be said to represent a system if the main characteristics of a system needed in making the model are available. For this reason, procedures related to warehousing in Dopusbektim are made in the form of data flow diagrams. Characteristics not included in the model are considered as limits. In modeling the system, the following steps are needed:

1) Learn and describe the system in terms of structural and functional by looking at the elements of the system that are related, the interaction between elements and conditions faced, so that existing problems can be determined and the objectives to be achieved can be known.

2) Form a conceptual model based on the description of the system which functions to obtain a basic description of the system to be created.

3) Making procedural flow and data flow diagrams for information systems.

c. System planning. Is a process of compiling or proposing an information system, where the results of the system designed must be in accordance with the needs of these problems. Design includes database design. Database design is a form of design that consists of several stages starting from the proposed system and procedures that are illustrated in the Data
Flow Diagram. Next, design the Entity Relationship Diagram (ERD) in the form of Conceptual Data Model (CDM), which is then converted into the Physical Data Model (PDM). Until finally the database design is made which is the database structure of the system that will be created.

d. Design Implementation. Is the application of the results of the design in the form of information system design software on the object of research.

\section{RESULTS AND DISCUSSION.}

Designing system requirements is the answer to identifying problems that are expected to overcome the problems that occur in the current system.

The warehousing system at Dopusbektim still uses the manual method in checking and recording in the warehouse that is recorded in the stock card. With the current system it is very possible for human error to occur in the distribution process of goods in the warehouse, in the progress of technological developments that are increasingly rapid so that the system requires some development. The warehousing system that runs in Dopusbektim is still not optimal because it has not been able to accommodate its warehousing needs. Warehousing requires a system that can be in real time to accommodate the needs of the system, such as a fast, easy and inexpensive warehousing process. The development of the warehousing process using RFID technology that integrates with computers in the Dopusbektim warehouse is the answer in overcoming these problems.

This discussion describes the process of hardware (RFID) management and software design that supports this warehousing information system and continues with a mechanism for the use of warehousing information systems. 


\subsection{Designing hardware}

In this paper we use low frequency RFID (125 Khz) RFID, which is usually used in daily necessities such as hotel room keys, payment cards on toll roads and so on. The tags used are passive tags in the form of cards and buttons. On the card a chip that functions as a store of information used to identify items contained in an item or box. Because the paper using low frequency RFID is not needed an antenna that is used to capture signals released by active tags in which there is an energy source (battery installed) to always emit a signal so that it can identify the item. The following is the RFID specification used in this study:

RFID type: ACR 120

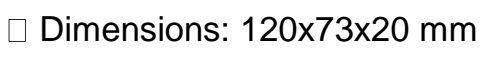

$\square$ Weight: $15 \mathrm{~g}$

$\square$ The operating distance: up to $5 \mathrm{~cm}$

$\square$ Supply voltage: $5 \mathrm{~V}$ DC

$\square$ Supply current: $200 \mathrm{~mA}$

$\square$ Smart card interface support: ISO 14443

Type A \& B, Mifare:

For RFID specifications it does have a disadvantage with very low read distance, but the ability to read tags by the reader is very good. Not only in RFID with this type that has disadvantages, RFID with Ultra High Frequency (UHF) also has advantages and disadvantages too. However, all of that depends on the application to be used. The price of readers for this type of low frequency RFID is cheaper compared to readers with a higher frequency than this type. RFID for warehousing information systems is required to use RFID with high frequency and also use active tags. By using these facilities, items that are in warehousing can be controlled in real time.

For servers or Personal Computers (PCs) themselves do not require anything excessive. The function of the PC itself as a place where the data captured by the reader will be processed by software and the results will be used for debriefing activities in the warehouse. In this paper used a laptop that has been connected with RFID using a USB cable.

For the software itself, the development uses $\mathrm{C}$ programming language and also uses HTML and PHP programming languages. C:> programming language is used in making applications for storing data into tag cards. This program is also used to create tag reader applications for the process of entering and leaving items. While the HTML programming language is used for the website creation process which is used as a forum for sharing information between fellow employees.

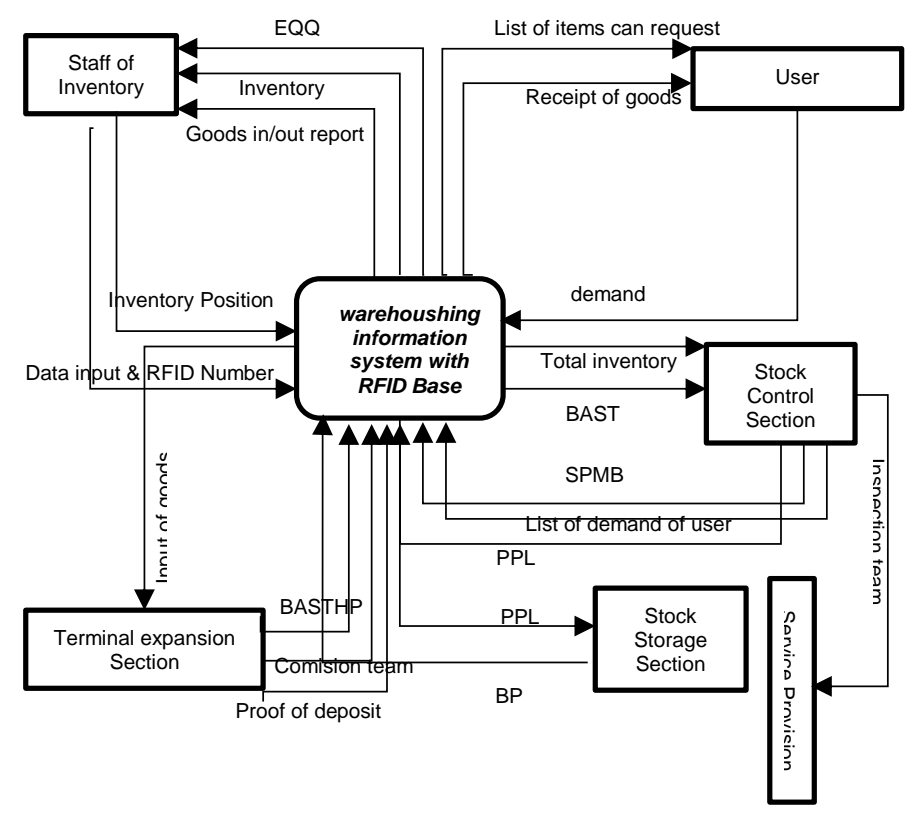

Gambar 3.1 Context Diagram of warehousing information systems with RFID Base

In Figure 3.2, Data Flow Diagrams (DFD) are the development of the main problems listed on the context diagram. From this DFD can be seen how the system runs. Basically the warehouse process that runs is divided into 2 processes, namely the flow of goods entering and the process of leaving the goods, which are described in DFD level 0 as in the following picture : 


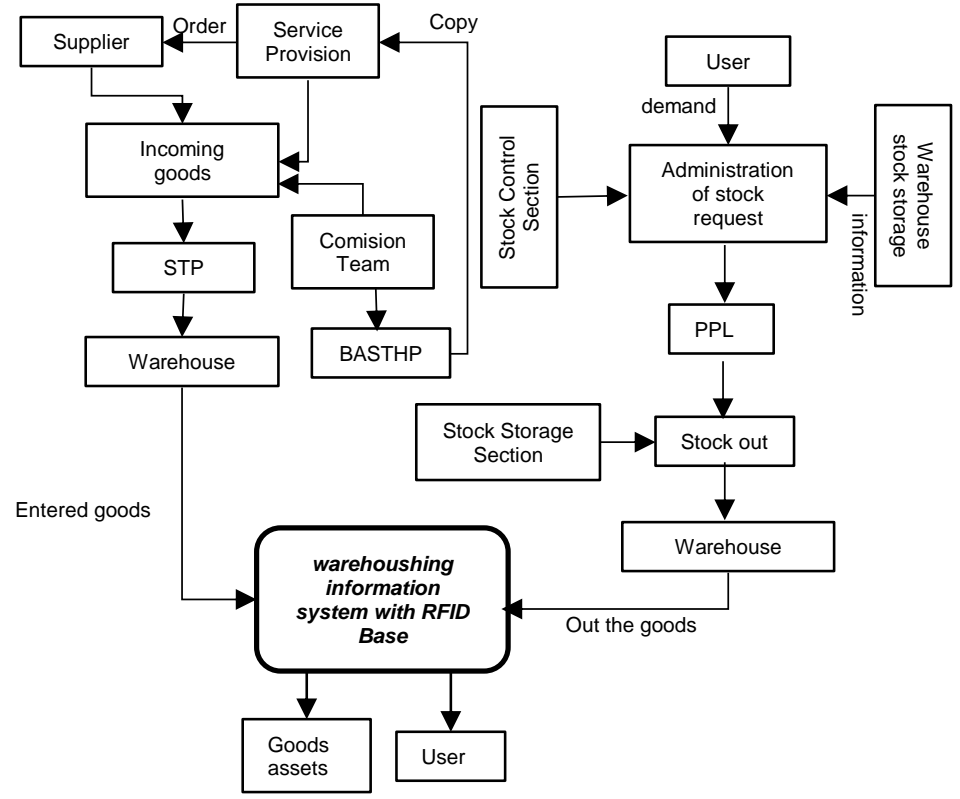

Figure 3.2 DFD level 0

In figure 3.3 the DFD level 1 sub-process of the provision describes the flow of provisions in and the documents in the form of invoices and permits and then the receipt of receipts in the form of safekeeping.

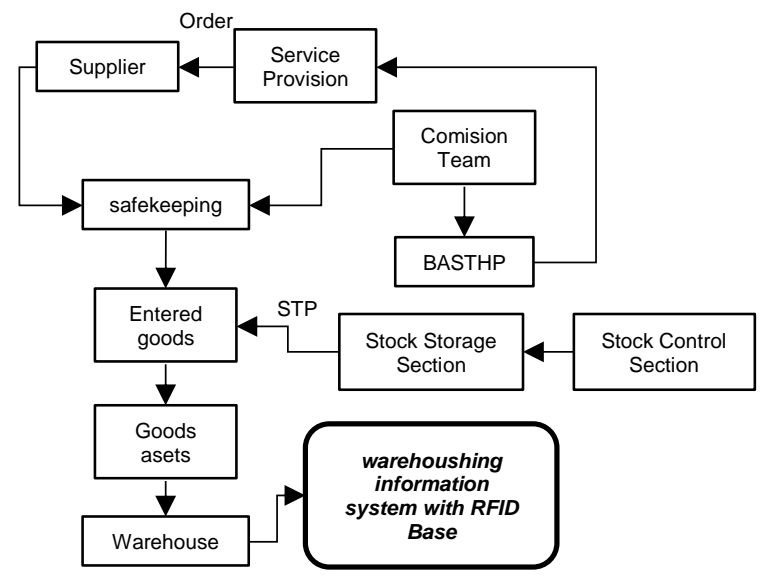

Figure 3.3 Level 1 DFD Sub Provision process

In figure 3.4 DFD Level 1 Sub Process Provision out explains how the provisions are distributed or issued. For DFD Level 1 sub-process spending, this process begins with the user submitting the request, then the request will be validated by the Stock Control Section based on stock information and check the completeness of the request, after the request meets the requirements Stock Control Section issued PPL, then Stock Storage Section issued Goods issuance letter and continued by the user to collect goods by scanning RFID tags in the item in the warehousing information system.

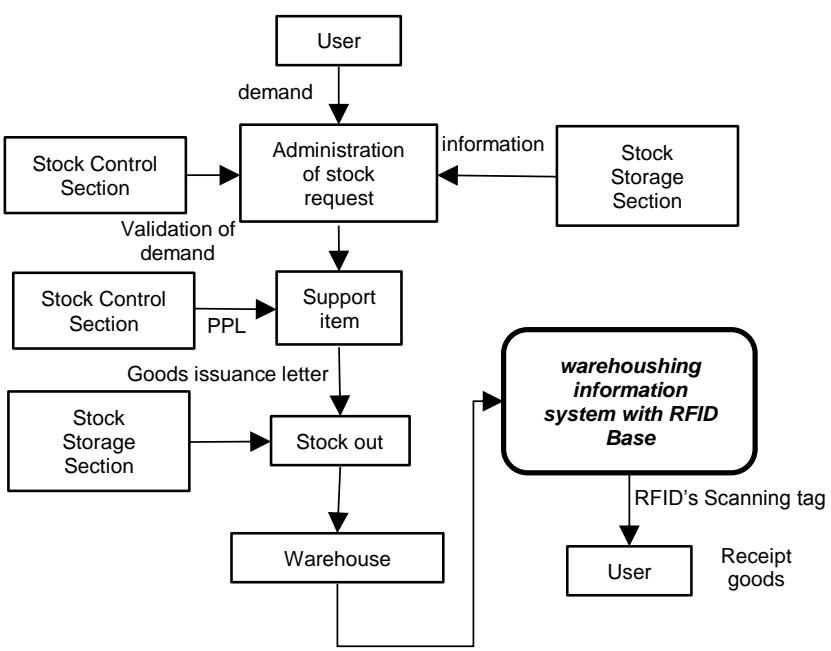

Figure 3.4 DFD Level 1 Sub The process of getting out.

In the picture 3.5 ERD is used to interpret, determine and document the requirements for database processing. In designing this system several interrelated entities are created to provide data needed by the system.

Figure 3.5 Entity Relation Diagram (ERD)

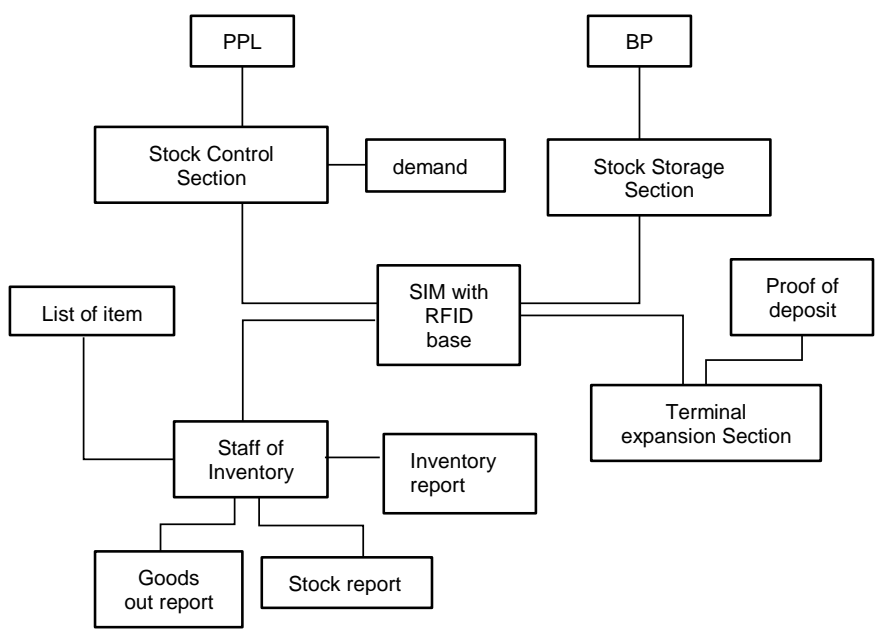

\subsection{Database Design}

Desktop applications and web interfaces are connected to a database that can be accessed via http: // localhost / phpmyadmin which is a unit with a 
pragram application called XAMPP. All required databases are created in the Phpmyadmin program which includes user databases ranging from users, inventory staff and management.

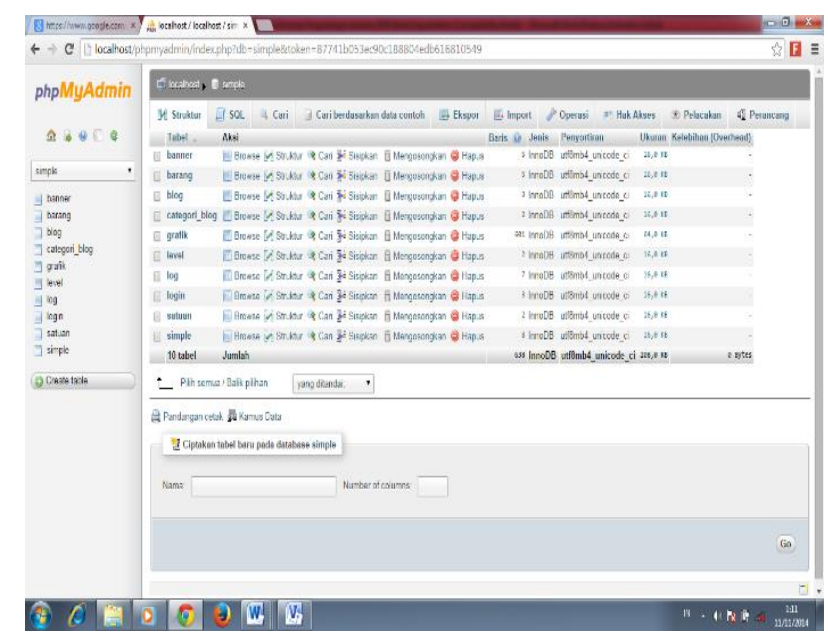

Figure 3.6 Database of RFID-based warehousing information systems.

To be able to access the database on this system, the computer or laptop must be able to access it through the browser. In the database admin can change the information that is on the system by pressing the edit button on the application interface. This database structure will interpret the ERD concept into a database form in the form of tables that describe the field names, functions and types, and size (width) of the field.

\section{CONCLUSION.}

1. From the results of evaluation and research This warehousing information system with an RFID base can assist in carrying out Dopusbektim tasks which include the following:

a. Facilitate inventory staff activities in checking and identifying items out.

b. Makes it easy to find stock locations quickly.

c. Makes it easy for users to get stock information that can be asked for.

d. Makes it easy for management to monitor out-of-stock activities.
2. It is expected that the application of the warehousing information system will run more optimally in supporting user needs.

3. Software applications are running well through testing 15 test cases without erorr and the results are as expected.

4. This research has produced a prototype of an RFID-based warehousing system design that can carry out recording activities automatically, connecting warehousing with the customer.

\section{REFERENCES}

Burch, J., \& Grudnitski, G. (1986). Information System Theory and Practice. New York: John Wiley and Son.

Davis, G. B. (1974). Management Information System: Conceptual Fondation, structure and Development. Auckland: Mc,Graw-Hill International book company.

Fitzgerald, J. F. (1981). Fundamentals Of System Analysis. New York: John Willey \& Sons.

Golburg, J. (2005). RFID Evaluation Kit. Adilam Electronic.

Hamid. (2010). Development of computerized parking systems with financing automation and RFID users as unique users. National Seminar on Information Technology Applications. Yogyakarta: Indonesian Islamic University.

Hartono, j. (2005). Information System Analysis \& Design Approach. Yogyakarta: Andi.

Kadir, A. (1999). The concept and practical guidance of the database. Yogyakarta: Andi.

Kaukab, M. (2008). Designing Mobile Radar Simulation. Jakarta: Faculty of Engineering, University of Indonesia.

Kuncoro, B. (2011). Build a Stock Information Service System in Dopusbekbar. Surabaya: STTAL Industrial Engineering Department. 
Ladjamudin, A. B. (2005). Information system analysis and design. Tangerang: Graha IImu.

McLeod. (2004). Management information System. Jakarta: PT Index.

McLeod, R. d. (2008). Management Information System, 10th. Salemba Empat

Simatupang, T. M. (1995). System modeling. Klaten: Nindita..

Unitedstates, G. A. (2005). Information Security: Radio Frekuensi Identification Technology in the Federal Goverment. http://www.gao.gov/new.items/d05551.pdf. 